\title{
Identification of the Viral Genes Responsible for Growth of Strains of Reovirus in Cultured Mouse Heart Cells
}

\author{
Yoshiki Matoba, ${ }^{\star *}$ Barbara Sherry, ${ }^{\ddagger}$ Bernard N. Fields, ${ }^{\star 5 \|}$ and Thomas W. Smith* \\ ${ }^{*}$ Cardiovascular Division, Department of Medicine, Brigham and Women's Hospital and Harvard Medical School; ${ }^{\ddagger}$ Department of \\ Microbiology and Molecular Genetics, Harvard Medical School; ${ }^{\$}$ Department of Medicine (Infectious Disease), \\ Brigham and Women's Hospital; and "Shipley Institute of Medicine, Boston, Massachusetts 02115
}

\begin{abstract}
Viral growth in specific tissue is usually required in order to lead to pathology. Two reovirus isolates (type 1 Lang and type 3 Dearing) differ in their capacity to grow in cultured mouse heart cells. The mammalian reoviruses contain a genome of 10 double-stranded RNA gene segments. By the use of 37 reassortant viruses (consisting of viruses with different combinations of genes derived from the two parents), difference in capacity of different strains to grow in heart cells was mapped to three different genes, all of which encode viral core proteins: the M1 gene $(P<0.000044)$; the L1 gene $(P=0.00094)$; and the L3 gene $(P=0.019)$. Using the same set of reassortant viruses, the $\mathrm{L1}(P=0.00015)$ and $\mathrm{L3}(P=0.0065)$ genes were involved in differences of the ability of viral strains to grow in mouse $L$ cells (fibroblasts), but the M1 gene $(P=0.12)$ was not. These findings suggest that the $M 1$ gene plays an important and specific role in determining the relative capacity of certain viral strains to grow in the heart. Thus, we have identified viral genes responsible for differing growth capacity in heart muscle cells in culture. These findings provide a novel system for studies of viral myocarditis at a molecular genetic level. (J. Clin. Invest. 1991. 87:1628-1633.) Key words: myocarditis • viral pathogenesis • the M1 gene
\end{abstract}

\section{Introduction}

Reoviruses have a genome composed of 10 double-stranded RNA segments. Because of this segmented genetic structure, reassortant viruses containing different combinations of gene segments can be derived from parental viruses by coinfecting cells with both serotypes (1). When two reovirus parents differ in a biological property, the progeny reassortant viruses can segregate the difference and thereby allow the identification of gene(s) that specify the difference (for reviews, see references 2 and 3). Using such genetic studies, functions of three outer capsid proteins (the $\sigma 1$ protein encoded by the S1 gene, the $\mu 1 \mathrm{C}$ protein encoded by the $\mathrm{M} 2$ gene, and the $\sigma 3$ protein encoded by the $\mathrm{S} 4$ gene) have been identified. The $\sigma 1$ protein is involved in cell attachment (4) and thereby contributes to the determination of cell and tissue tropism (5). The $\mu 1 \mathrm{C}$ protein determines the interaction with proteases (6) and modulates neuroviru-

Address correspondence and reprint requests to Dr. Thomas W. Smith, Cardiovascular Division, Brigham and Woman's Hospital, 75 Francis Street, Boston, MA 02115.

Received for publication 27 August 1990 and in revised form 28 December 1990.

J. Clin. Invest.

(c) The American Society for Clinical Investigation, Inc. $0021-9738 / 91 / 05 / 1628 / 06 \$ 2.00$

Volume 87, May 1991, 1628-1633 lence (7). The $\sigma 3$ protein is involved in inhibition of cellular RNA and protein synthesis (8) and establishment of persistent infection (9). Little is known about the function of core proteins. Recently, an efficiently myocarditic reovirus strain (designated 8B) was isolated and characterized (10). The myocarditic phenotype of the 8B isolate in mice is associated with a mutation(s) in the Ml gene, which encodes a viral core protein of unknown function (11). Whether the M1 gene also plays a more general role in determining growth in myocardial cells, has not been determined.

Growth of a virus in specific cells is often required in order to lead to pathology. Therefore, an understanding of viral determinants necessary for growth in heart tissue is important for elucidating the pathogenesis of viral myocarditis. Reovirus is an attractive model in which to study how viruses cause myocarditis at a molecular genetic level. In this study, we established a mouse heart cell culture system in which to study reovirus replication. We evaluated the genes involved in determining differences in replication of our two prototype laboratory strains (type 1 Lang and type 3 Dearing). Our findings indicate that the M1 gene plays an important role in determining the capacity of reoviruses to grow in heart cells in culture.

\section{Methods}

Cultured heart cells. Heart cell cultures were prepared from the hearts of fetal (18-20 d) and neonatal (within $48 \mathrm{~h}$ postpartum) National Institutes of Health (NIH) Swiss mice (National Cancer Institute, Frederic, MD) by modification of the method previously used for neonatal rat cultured heart cells (12). Briefly, the hearts were removed from ether-anesthetized mice, and cells were dispersed in $0.25 \%$ trypsin (Gibco Laboratories, Grand Island, NY) with 1 mM EGTA. Cell suspensions were washed in Dulbecco's modified Eagle's medium (DME) supplemented with $7 \% \mathrm{FCS}$, thymidine $(600 \mu \mathrm{g} / \mathrm{ml})$, and antibiotics ( $20 \mathrm{U} / \mathrm{ml}$ penicillin, $20 \mu \mathrm{g} / \mathrm{ml}$ streptomycin, and $20 \mu \mathrm{g} / \mathrm{ml}$ gentamicin), and enriched with myocytes by preplating in 6-well clusters (Costar Corp., Cambridge, MA) for $2 \mathrm{~h}$ at $37^{\circ} \mathrm{C}$. Residual unattached cells were diluted with the same medium and plated in 24-well clusters (Costar Corp.) at a density of $2.0 \times 10^{5}$ cells $/ \mathrm{cm}^{2}$.

L cells and viruses. Mouse L929(L) cells were propagated in suspension in the Joklik modification of Eagle's minimal essential medium (MEM) supplemented with $2.5 \%$ FCS and $2.5 \%$ viable serum protein (VSP) $^{1}$ as described previously (10). L cells were diluted with MEM and plated in 24-well clusters at a density of $2.4 \times 10^{4}$ cells $/ \mathrm{cm}^{2}$. Reovirus type 1 Lang (T1L) and type 3 Dearing (T3D) were from standard laboratory stocks (13). T3D stocks themselves differ in their capacity for growth in mouse $\mathrm{L}$ cells, and this study used poorly growing T3D stocks to maximize the difference in growth compared with T1L. Reassortant viruses used in this study (EB series) were prepared by Brown et al. (14).

1. Abbreviations used in this paper: MOI, multiplicity of infection; T1L, reovirus type 1 Lang; T3D, type 3 Dearing; VSP, viable serum protein. 
Infection of cells. $2 \mathrm{~d}$ after preparing the cultured mouse heart cells, two wells were trypsinized and viable cells were counted using the trypan blue exclusion method. The cultured heart cells were infected with $100 \mu \mathrm{l}$ of reovirus (T1L or T3D, or reassortants) at a multiplicity of infection (MOI) of 3 (virus:cell $=3: 1$ ), and incubated for $1 \mathrm{~h}$ at $37^{\circ} \mathrm{C}$ with intermittent rocking. Then $900 \mu \mathrm{l}$ of DME with insulin $(5 \mu \mathrm{g} / \mathrm{ml})$, transferrin $(5 \mu \mathrm{g} / \mathrm{ml})$, and selenium $(5 \mathrm{ng} / \mathrm{ml})$ in the absence of FCS was added. Inoculation of $L$ cells was performed by a similar method, except that they were infected $1 \mathrm{~d}$ after plating the cells, and the overlaying medium was MEM with 2.5\% FCS and 2.5\% VSP. To compare the difference of growth of T1L and T3D reovirus strains, infection was terminated by freezing the clusters every day from day 1 to day 5 , and reassortment studies were done on day 4 after infection.

Viral titer determination. Cells in 24-well clusters were frozen $\left(-70^{\circ} \mathrm{C}\right)$ and thawed $\left(37^{\circ} \mathrm{C}\right)$ three times and disrupted by sonication (10). The viral suspensions were serially diluted in 10-fold steps in gel saline and plated in duplicate on $\mathrm{L}$ cell monolayers for plaque assays as described previously (15). Viral titers were expressed as PFU per cell (cultured heart cell or $\mathrm{L}$ cell).

Statistical analysis. Reassortant viruses in Tables I and II were ordered by viral yields and then assigned a rank consistent with this order. The Wilcoxon rank sum analysis was applied (16).

\section{Results}

Growth of reovirus in cultured heart cells. In the heart in vivo, $\mathrm{T} 1 \mathrm{~L}$ replicates to a higher titer than T3D ( 2 to $3 \log _{10}$ difference between 3 and $9 \mathrm{~d}$ after injection of the viruses into the intact mice) (10). Although myocytes occupy over two-thirds of the volume of the myocardium, their number in the myocardium relative to total cells present is no more than one third; fibroblasts, blood vessel cells, and other cellular elements represent another two-thirds of the cells $(17,18)$. To compare the growth of reovirus in cultured myocytes under carefully controlled conditions, we used cultured mouse heart cells in this study. As Fig. 1 shows, T1L grew to a higher titer than T3D ( $2 \log _{10}$ difference between 3 and $5 \mathrm{~d}$ after infection) in cardiac myocytes in vitro, and both serotypes reached a plateau of growth by $4 \mathrm{~d}$ after infection at a MOI of 3 .

Reassortment study in cultured heart cells. To identify the genes responsible for the differing growth capacity of the two strains, we tested reassortants between these parental viruses (EB series) for their capacity to grow in cultured mouse cardiac myocytes. In Table I, reassortant viruses are placed in order of maximal viral yield from the top, and T1L and T3D are also included for reference. The viral yield of T1L was almost the highest, and that of T3D was almost the lowest, and those of reassortants tended to span a continuum between them. It was difficult to draw a clear boundary between higher and lower



Figure 1. Growth of reovirus (type 1 Lang $[T 1 L]$ and type 3 Dearing $[T 3 D]$ ) in cultured mouse heart cells. Cultured heart cells were infected (virus:cell $=3: 1) 2 \mathrm{~d}$ after preparing primary cell cultures (day 0 ), and were frozen on the day indicated.

Viral yields were determined by plaque assay as described in Methods. Each time point represents the mean of two samples. The standard deviation is $<0.11 \log _{10}$ at all time points. viral yields. Accordingly, we applied a Wilcoxon rank sum analysis, in which the data were treated as a continuum spanning the range from lowest to highest. For each gene segment, ranks for those derived from T1L or T3D were summed up separately, and these values were compared with those in statistical tables (16). When the sum of ranks fell outside the limits at a given $P$ value in the table, the next highest $P$ value was examined, until the $P$ value identified within the sum of ranks fell. By the use of 37 reassortant viruses, differing growth capacity of the reoviral reassortants in cultured heart cells could be attributed to three different genes (values of $P<0.05$ were taken as statistically significant), all of which encode viral core proteins: the M1 gene $(P<0.000044)$; the Ll gene $(P=0.00094)$; and the L3 gene $(P=0.019)$ (Table III). Notably, EB 39, which has only two gene segments (M1 and L1) derived from T1L with the other eight genes derived from T3D, still grew to a high titer. As a trend, viruses whose $\mathrm{M} 1$ and $\mathrm{Ll}$ genes were derived from T1L comprised a higher viral yield group, and viruses where these genes were derived from T3D comprised a lower yield group. Viruses that have T1L-M1/T3D-L1 or T3D-M1/ T1L-L1 genes comprised an intermediate group. However, EB 144 , whose $M 1, L 1$, and $L 3$ genes were derived from $T 1 L$, did not grow to as high a viral titer as expected from the trend just cited, and was therefore an exception.

Growth of reovirus in $L$ cells. To confirm whether these three genes were related to observed growth in myocytes specifically or played a role in the growth in other types of cells, we examined the growth of reovirus in the $L$ cell line generally used for propagation and titration of the reoviruses. As Fig. 2 shows, T1L also replicated much more than T3D in L cells, and both serotypes reached a plateau of growth by $4 \mathrm{~d}$ after infection at a MOI of 3. Therefore, T1L grew better than T3D in $\mathrm{L}$ cells as well as in myocytes.

Reassortment study in L cells. A reassortment analysis was performed in L cells using the same set of reassortant viruses as in cultured heart cells. In Table II, reassortant viruses are placed in order of maximal viral yield from the top, and T1L and T3D are also included for reference. The viral yield of T1L was almost the highest and that of T3D was almost the lowest, and those of the reovirus reassortants spanned the range between them. We also applied a Wilcoxon rank sum analysis, and by the use of 33 reassortant viruses, differing growth capacity in $\mathrm{L}$ cells could be mapped to two different genes: the L1 gene $(P=0.00015)$; and the L3 gene $(P=0.0065)$ (Table III). However the M1 gene, which was the most significantly different in cultured mouse heart cells, was not related at all to the difference in virus growth in $\mathrm{L}$ cells.

\section{Discussion}

In this study, we found that the M1 gene was the primary reovirus gene that determined the relative capacity of our laboratory strains to grow in myocardial cells in vitro. This study, using reassortants derived from laboratory isolates (T1L and T3D), thus extends prior mapping of the M1 gene of a myocarditic variant (8B) to its capacity to produce myocarditis in a mouse system (11).

Reovirus causes a variety of diseases in mice (for a review, see reference 3) including myocarditis (19-23). However, these reports are limited to descriptions of pathologic changes of the heart tissue and detection of virus using histopathologic, electron microscopic, and in situ hybridization methods. Recently, 


\begin{tabular}{|c|c|c|c|c|c|c|c|c|c|c|c|c|}
\hline \multirow{2}{*}{ Virus } & \multicolumn{10}{|c|}{ Origin of gene segment encoding } & \multirow[b]{2}{*}{ Viral yield } & \multirow[b]{2}{*}{ Rank } \\
\hline & L1 & L2 & L3 & M1 & S2 & s1 & M2 & S4 & M3 & s3 & & \\
\hline & & & & & & & & & & & $(P F U /$ cell $) \times 10$ & \\
\hline EB 85 & 1 & 1 & 1 & 1 & 3 & 1 & 1 & 1 & 3 & 1 & $1625 \pm 205$ & 37 \\
\hline $\mathrm{T} 1 \mathrm{~L}$ & 1 & 1 & 1 & 1 & 1 & 1 & 1 & 1 & 1 & 1 & $1462 \pm 237$ & \\
\hline EB 93 & 1 & 1 & 1 & 1 & 1 & 1 & 1 & 1 & 1 & 3 & $1412 \pm 141$ & 36 \\
\hline EB 74 & 1 & 3 & 1 & 1 & 1 & 1 & 1 & 1 & 1 & 3 & $1362 \pm 264$ & 35 \\
\hline EB 98 & 1 & 3 & 1 & 1 & 3 & 1 & 1 & 3 & 1 & 1 & $1287 \pm 80$ & 34 \\
\hline EB 39 & 1 & 3 & 3 & 1 & 3 & 3 & 3 & 3 & 3 & 3 & $1216 \pm 287$ & 33 \\
\hline EB 68 & 1 & 3 & 1 & 1 & 1 & 1 & 3 & 3 & 1 & 3 & $1087 \pm 363$ & 32 \\
\hline EB 87 & 1 & 3 & 1 & 1 & 3 & 1 & 3 & 1 & 1 & 1 & $904 \pm 238$ & 31 \\
\hline EB 143 & 3 & 1 & 1 & 1 & 1 & 3 & 1 & 1 & 1 & 1 & $741 \pm 227$ & 30 \\
\hline EB 47 & 1 & 3 & 1 & 1 & 1 & 1 & 1 & 1 & 1 & 1 & $720 \pm 189$ & 29 \\
\hline EB 136 & 3 & 3 & 3 & 1 & 3 & 3 & 3 & 3 & 1 & 3 & $633 \pm 158$ & 28 \\
\hline EB 31 & 1 & 1 & 1 & 3 & 3 & 1 & 1 & 1 & 1 & 3 & $504 \pm 43$ & 27 \\
\hline EB 28 & 3 & 3 & 1 & 3 & 1 & 3 & 3 & 3 & 3 & 3 & $462 \pm 168$ & 26 \\
\hline EB 120 & 3 & 3 & 3 & 1 & 3 & 3 & 1 & 1 & 3 & 1 & $400 \pm 37$ & 25 \\
\hline EB 113 & 1 & 1 & 1 & 3 & 1 & 1 & 1 & 1 & 1 & 3 & $395 \pm 31$ & 24 \\
\hline EB 108 & 1 & 3 & 1 & 3 & 1 & 1 & 1 & 3 & 1 & 3 & $379 \pm 162$ & 23 \\
\hline EB 97 & 3 & 3 & 1 & 3 & 3 & 3 & 3 & 1 & 3 & 3 & $362 \pm 150$ & 22 \\
\hline EB 127 & 3 & 3 & 1 & 1 & 3 & 1 & 3 & 1 & 1 & 3 & $342 \pm 50$ & 21 \\
\hline EB 140 & 3 & 3 & 1 & 1 & 1 & 1 & 1 & 1 & 1 & 3 & $329 \pm 48$ & 20 \\
\hline EB 146 & 1 & 1 & 1 & 3 & 1 & 1 & 1 & 3 & 1 & 1 & $256 \pm 49$ & 19 \\
\hline EB 15 & 3 & 3 & 1 & 1 & 3 & 1 & 1 & 3 & 3 & 1 & $219 \pm 39$ & 18 \\
\hline EB 132 & 3 & 3 & 1 & 3 & 3 & 3 & 3 & 1 & 1 & 3 & $187 \pm 47$ & 17 \\
\hline EB 62 & 3 & 3 & 3 & 3 & 1 & 3 & 3 & 1 & 3 & 3 & $183 \pm 49$ & 16 \\
\hline EB 109 & 3 & 3 & 1 & 3 & 3 & 1 & 3 & 3 & 3 & 3 & $176 \pm 53$ & 15 \\
\hline EB 86 & 1 & 3 & 3 & 3 & 3 & 3 & 3 & 1 & 1 & 3 & $161 \pm 6$ & 14 \\
\hline EB 129 & 3 & 3 & 1 & 3 & 1 & 3 & 3 & 3 & 1 & 1 & $147 \pm 35$ & 13 \\
\hline EB 144 & 1 & 1 & 1 & 1 & 1 & 1 & 3 & 1 & 3 & 3 & $146 \pm 34$ & 12 \\
\hline EB 18 & 3 & 3 & 1 & 3 & 1 & 1 & 3 & 1 & 3 & 3 & $116 \pm 35$ & 11 \\
\hline EB 128 & 3 & 3 & 1 & 3 & 3 & 1 & 3 & 1 & 3 & 3 & $115 \pm 40$ & 10 \\
\hline EB 138 & 3 & 1 & 1 & 3 & 3 & 3 & 3 & 1 & 1 & 1 & $114 \pm 36$ & 9 \\
\hline EB 142 & 3 & 3 & 1 & 3 & 3 & 1 & 1 & 1 & 1 & 3 & $105 \pm 32$ & 8 \\
\hline EB 88 & 3 & 3 & 3 & 3 & 3 & 3 & 1 & 3 & 3 & 3 & $85 \pm 9$ & 7 \\
\hline EB 96 & 1 & 3 & 1 & 3 & 1 & 1 & 1 & 1 & 1 & 3 & $75 \pm 8$ & 6 \\
\hline EB 73 & 3 & 3 & 3 & 3 & 3 & 3 & 3 & 1 & 1 & 1 & $66 \pm 30$ & 5 \\
\hline EB 13 & 3 & 3 & 3 & 3 & 3 & 3 & 3 & 1 & 3 & 3 & $26 \pm 5$ & 4 \\
\hline T3D & 3 & 3 & 3 & 3 & 3 & 3 & 3 & 3 & 3 & 3 & $25 \pm 8$ & \\
\hline EB 133 & 3 & 3 & 3 & 3 & 3 & 3 & 1 & 1 & 1 & 1 & $8 \pm 3$ & 3 \\
\hline EB 147 & 3 & 3 & 3 & 3 & 3 & 1 & 3 & 1 & 1 & 1 & $7 \pm 1$ & 2 \\
\hline EB 124 & 3 & 3 & 3 & 3 & 1 & 3 & 1 & 1 & 3 & 1 & $6 \pm 3$ & 1 \\
\hline
\end{tabular}

37 reassortant viruses were used for this study, and gene segments from type 1 Lang $(T 1 L)$ and type 3 Dearing $(T 3 D)$ are designated 1 or 3 . Viral yields are expressed as mean \pm SD from three wells except EB 127, 86, and 124, which are from two wells. The data from T1L and T3D are not included for the rank, because these viruses are the parents of the other viruses, and have different backgrounds. The significant levels attained by the rank sum for a given gene are shown in Table III.

Sherry et al. succeeded in isolating an efficiently myocarditic reovirus strain (designated $8 \mathrm{~B}$ ), derived by in vivo reassortment between nonmyocarditic parent reoviruses (T1L and T3D) (10). 8B contained two gene segments (S1 and M2) derived from T3D and the other eight gene segments derived from T1L. By reassortment study between $8 \mathrm{~B}$ and nonmyocarditic reoviruses whose gene segments were opposite of those of $8 \mathrm{~B}$, the capacity of $8 \mathrm{~B}$ to cause myocarditis was found to be associated with the M1 gene. Because of the nonmyocarditic pheno- type of both parent viruses, a mutation(s) in the $\mathrm{M} 1$ gene of $8 \mathrm{~B}$ was postulated (11). There also is a clinical case report of myocarditis in a 10-mo-old infant caused by reovirus (24). However, compared with Coxsackieviruses, which have been implicated frequently as pathogens in clinical myocarditis (for a review, see reference 25), the importance of reoviruses as a cause of clinical myocarditis has been difficult to ascertain because of their ubiquity and the common absence of symptoms associated with infection. 
Table II. Reovirus Reassortants Used to Map the Ability of Reovirus to Grow in L Cells

\begin{tabular}{|c|c|c|c|c|c|c|c|c|c|c|c|c|}
\hline \multirow[b]{2}{*}{ Virus } & \multicolumn{10}{|c|}{ Origin of gene segment encoding } & \multirow[b]{2}{*}{ Viral yield } & \multirow[b]{2}{*}{ Rank } \\
\hline & L1 & L2 & L3 & M1 & S2 & S1 & M2 & S4 & M3 & s3 & & \\
\hline & & & & & & & & & & & $(\mathrm{PFU} / \mathrm{cell}) \times 10^{2}$ & \\
\hline EB 143 & 3 & 1 & 1 & 1 & 1 & 3 & 1 & 1 & 1 & 1 & $1140 \pm 302$ & 33 \\
\hline T1L & 1 & 1 & 1 & 1 & 1 & 1 & 1 & 1 & 1 & 1 & $1052 \pm 73$ & \\
\hline EB 85 & 1 & 1 & 1 & 1 & 3 & 1 & 1 & 1 & 3 & 1 & $1010 \pm 98$ & 32 \\
\hline EB 108 & 1 & 3 & 1 & 3 & 1 & 1 & 1 & 3 & 1 & 3 & $880 \pm 108$ & 31 \\
\hline EB 93 & 1 & 1 & 1 & 1 & 1 & 1 & 1 & 1 & 1 & 3 & $791 \pm 108$ & 30 \\
\hline EB 74 & 1 & 3 & 1 & 1 & 1 & 1 & 1 & 1 & 1 & 3 & $562 \pm 34$ & 29 \\
\hline EB 87 & 1 & 3 & 1 & 1 & 3 & 1 & 3 & 1 & 1 & 1 & $429 \pm 27$ & 28 \\
\hline EB 97 & 3 & 3 & 1 & 3 & 3 & 3 & 3 & 1 & 3 & 3 & $427 \pm 27$ & 26.5 \\
\hline EB 39 & 1 & 3 & 3 & 1 & 3 & 3 & 3 & 3 & 3 & 3 & $427 \pm 39$ & 26.5 \\
\hline EB 128 & 3 & 3 & 1 & 3 & 3 & 1 & 3 & 1 & 3 & 3 & $421 \pm 71$ & 25 \\
\hline EB 109 & 3 & 3 & 1 & 3 & 3 & 1 & 3 & 3 & 3 & 3 & $320 \pm 3$ & 24 \\
\hline EB 68 & 1 & 3 & 1 & 1 & 1 & 1 & 3 & 3 & 1 & 3 & $303 \pm 26$ & 23 \\
\hline EB 146 & 1 & 1 & 1 & 3 & 1 & 1 & 1 & 3 & 1 & 1 & $278 \pm 22$ & 22 \\
\hline EB 113 & 1 & 1 & 1 & 3 & 1 & 1 & 1 & 1 & 1 & 3 & $260 \pm 15$ & 21 \\
\hline EB 127 & 3 & 3 & 1 & 1 & 3 & 1 & 3 & 1 & 1 & 3 & $251 \pm 10$ & 20 \\
\hline EB 144 & 1 & 1 & 1 & 1 & 1 & 1 & 3 & 1 & 3 & 3 & $222 \pm 24$ & 19 \\
\hline EB 129 & 3 & 3 & 1 & 3 & 1 & 3 & 3 & 3 & 1 & 1 & $208 \pm 24$ & 18 \\
\hline EB 47 & 1 & 3 & 1 & 1 & 1 & 1 & 1 & 1 & 1 & 1 & $181 \pm 11$ & 17 \\
\hline EB 98 & 1 & 3 & 1 & 1 & 3 & 1 & 1 & 3 & 1 & 1 & $175 \pm 12$ & 16 \\
\hline EB 18 & 3 & 3 & 1 & 3 & 1 & 1 & 3 & 1 & 3 & 3 & $169 \pm 7$ & 15 \\
\hline EB 120 & 3 & 3 & 3 & 1 & 3 & 3 & 1 & 1 & 3 & 1 & $157 \pm 32$ & 14 \\
\hline EB 96 & 1 & 3 & 1 & 3 & 1 & 1 & 1 & 1 & 1 & 3 & $153 \pm 5$ & 13 \\
\hline EB 62 & 3 & 3 & 3 & 3 & 1 & 3 & 3 & 1 & 3 & 3 & $145 \pm 18$ & 12 \\
\hline EB 123 & 3 & 3 & 1 & 3 & 3 & 3 & 3 & 1 & 3 & 1 & $141 \pm 21$ & 11 \\
\hline EB 28 & 3 & 3 & 1 & 3 & 1 & 3 & 3 & 3 & 3 & 3 & $123 \pm 16$ & 10 \\
\hline EB 88 & 3 & 3 & 3 & 3 & 3 & 3 & 1 & 3 & 3 & 3 & $108 \pm 4$ & 9 \\
\hline EB 13 & 3 & 3 & 3 & 3 & 3 & 3 & 3 & 1 & 3 & 3 & $88 \pm 7$ & 8 \\
\hline EB 73 & 3 & 3 & 3 & 3 & 3 & 3 & 3 & 1 & 1 & 1 & $83 \pm 17$ & 7 \\
\hline EB 138 & 3 & 1 & 1 & 3 & 3 & 3 & 3 & 1 & 1 & 1 & $72 \pm 8$ & 6 \\
\hline EB 136 & 3 & 3 & 3 & 1 & 3 & 3 & 3 & 3 & 1 & 3 & $58 \pm 6$ & 5 \\
\hline EB 140 & 3 & 3 & 1 & 1 & 1 & 1 & 1 & 1 & 1 & 3 & $51 \pm 5$ & 4 \\
\hline EB 133 & 3 & 3 & 3 & 3 & 3 & 3 & 1 & 1 & 1 & 1 & $40 \pm 3$ & 3 \\
\hline EB 15 & 3 & 3 & 1 & 1 & 3 & 1 & 1 & 3 & 3 & 1 & $26 \pm 2$ & 2 \\
\hline T3D & 3 & 3 & 3 & 3 & 3 & 3 & 3 & 3 & 3 & 3 & $26 \pm 1$ & \\
\hline EB 147 & 3 & 3 & 3 & 3 & 3 & 1 & 3 & 1 & 1 & 1 & $24 \pm 3$ & 1 \\
\hline
\end{tabular}

33 reassortant viruses were used for this study. The decreased number of viruses compared with Table I (37 reassortant viruses) for cultured heart cells came from miscalculation of original titers of some viruses (EB31, 86, 124, 132). Gene segments from type 1 Lang (T1L) and type 3 Dearing $(T 3 D)$ are designated 1 or 3 . Viral yields are expressed as means \pm SD from three wells except EB 123 , which is from two wells. The data from T1L and T3D are not included for the rank, because these viruses are the parents of other viruses, and have different backgrounds. The significance levels attained by the rank sum for a given gene are shown in Table III.

To elucidate the mechanisms of viral myocarditis, much effort has been directed toward the immune response of the host, and relatively little analysis has been done based on studies of the viruses themselves. Duke et al. (26) showed the importance of the long homopolymeric poly $(C)$ tracts in $5^{\prime}$ noncoding sequences of Mengo virus (murine cardiovirus) for its pathogenicity. Schwimmbeck et al. (27) reported that Coxsackievirus B3 has homology with the main autoimmunologic epitope of the adenine nucleotide translocator, one of the autoantigens thought to be associated with myocarditis and dilated cardiomyopathy (28). Beisel et al. (29) identified an antigenic epitope shared between Coxsackievirus B4 and murine alpha cardiac myosin heavy chain, which is also thought to be an autoantigen in myocarditis (30). Reovirus is an attractive model in which to address viral myocarditis from the viral aspects because of its known capacity to produce myocarditis, the detailed information on its genetics, and the relative ease with which its genome can be manipulated.

Viral pathogenesis, the process by which a virus causes disease, is determined by virus, host, and their interaction. Growth of a virus in a host cell is a major step in viral pathogenesis, and in viral myocarditis the viral titer in the heart is generally related to histopathologic lesions (31). However, despite equivalent viral titers in the heart, certain viruses cause varying 


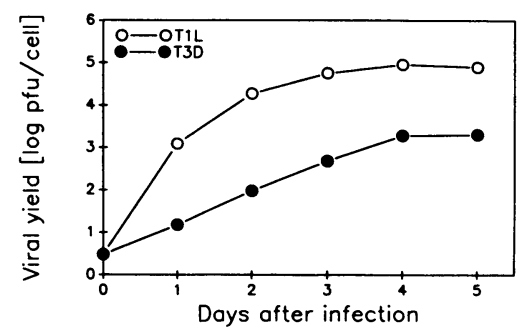

as described in Methods. Each time point represents the mean of three samples. The standard deviation is $<0.11 \log _{10}$ at all time points.

lesions of myocarditis depending on specific genetic aspects of the host animal $(32,33)$. Variants of the same virus also differ in the capacity to induce myocarditis. For example, a strain of Coxsackievirus $\left(\mathrm{CVB}_{\mathrm{M}}\right)$ produced moderate to severe myocardial lesions in adult CD-1 mice, while a variant of same virus $\left(\mathrm{CVB}_{\mathrm{O}}\right)$ induced few or no cardiac lesions in the same animal model (34). This might be explained by differences in viral replication in the heart $\left(\mathrm{CVB}_{\mathrm{M}}>\mathrm{CVB} 3_{\mathrm{O}}\right)$. In the case of reoviruses, the $8 \mathrm{~B}$ variant is highly myocarditic, while $\mathrm{T} 1 \mathrm{~L}$, despite almost equivalent viral titers in the heart, causes few lesions in intact neonatal NIH-Swiss mice (10). Thus, the importance of differences in viral growth in the heart in the pathogenesis of myocarditis is still unclear, but understanding what determines differences in viral growth in myocytes is necessary to elucidate the pathogenesis of myocarditis.

The growth of reovirus has been studied in some specific organ systems: brains (35), primary neuronal cell cultures (36), eyes (37), pancreatic islet and pituitary cell lines (38), and intestinal tissue (39). The S1 gene was related to the growth in neuronal tissue, and the S1 and L2 genes were related to growth in intestinal tissue. Both of these genes encode outer capsid proteins, and the roles of inner core proteins on the growth of reovirus in any tissue have not yet been established.

Table III. Relative Contribution of the 10 Reovirus Gene Segments Estimated by Wilcoxon Two-Sample Test Analysis

\begin{tabular}{lll}
\hline$P$ value & \multicolumn{1}{c}{ Cultured heart cells } & \multicolumn{1}{c}{ L cells } \\
\hline 0.1 & L2, S2, S1, M2, S4, M3, S3 & M1, S2, M2, S4, M3, S3 \\
0.05 & & L2, S1 \\
0.02 & & \\
0.01 & L3 & L3 \\
0.005 & & \\
0.002 & & L1 \\
0.001 & & \\
0.0005 & L1 & \\
$<0.0005$ & M1 &
\end{tabular}

The Wilcoxon rank sum analysis (Lentner, 1982) was applied to examine the relative contribution of each veovirus gene segment on viral growth in cultured heart cells (Table I) ad L cells (Table II). The average viral yields were used to rank reassortant viruses, and in each gene segment ranks were summed up separately whether the gene segment was derived from type 1 Lang or type 3 Dearing. When the sum of ranks fell outside the limits at a given $P$ value in the table, the next highest $P$ value was examined until the $P$ values identified within the sum of ranks fell.
In this study, we found that the M1 gene $(P<0.000044)$, the $\mathrm{L} 1$ gene $(P=0.00094)$, and the $\mathrm{L} 3$ gene $(P=0.019)$ correlated with differing growth capacity in the heart, while only the L1 $(P=0.00015)$ and L3 genes $(P=0.0065)$ were so correlated in $L$ cells. From the levels of statistical significance and comparison between cultured heart cells and L cells, relationships emerge between these genes and viral growth.

1. The $M 1$ and $L 1$ gene effects were more statistically significant than the $\mathrm{L} 3$ gene effect, and the $\mathrm{M} 1$ and $\mathrm{L} 1$ genes encode proteins that are found as 12 copies per virus particle (2). As Sherry et al. noted (11), these low copy numbers suggest two possible roles: as an enzyme activity involved in RNA synthesis; and as a structural element based on the location of the protein at the icosahedral vertices (there are 12 vertices per viral particle). The former might be related to the replication of the virus, and the latter to the structural stability of the virus. It is worth noting that the $\mathrm{L} 1$ gene has been implicated genetically as having a role in RNA synthesis (40), and the L1 sequence contains a polymerase motif (41). From the coincidence of the 12 copies per viral particle and the 12 vertices, the possibility that the products of the $\mathrm{M} 1$ and $\mathrm{L} 1$ genes cooperate structurally is of interest.

2. The $\mathrm{L} 1$ and $\mathrm{L} 3$ genes were found to be correlated with viral growth in nonmyocytes. It is thus possible that these two genes are related to the growth of virus in cells generally, while the M1 gene determines some function(s) specific to the heart. While tropism to the cardiac myocyte is one such possibility, in reovirus the $\mathrm{S} 1$ gene, which encodes the outer capsid protein, is thought to be most closely related to cell and tissue tropism (5). Thus, how the M1 gene influences cardiac growth and tropism is at present unclear.

3. In spite of some efforts to remove nonmyocytes from cultured heart cells $(2 \mathrm{~h}$ of preplating, use of thymidine and serum-free medium), there may still be a small degree of contamination of nonmyocytes in primary heart cell cultures. Thus, another possibility is that the M1 gene is related to viral growth in myocytes and involvement of the $\mathrm{L} 1$ and $\mathrm{L} 3$ genes is a reflection of the growth of nonmyocytes as observed in $L$ cells, although the nature of the $\mathrm{L}$ cell (fibroblast cell line, not identical with fibroblasts in vivo) differs from that of nonmyocytes in primary cultures of heart cells.

Whatever the mechanism, this study indicates that the M1 gene plays an important role in reovirus growth in the heart. It is of particular interest that a mutation(s) in the M1 gene converts a nonmyocarditic to a myocarditic virus, although both viruses grow to high titers in the heart. Altered structure or function related to viral growth in the heart may allow the virus to become myocarditic, although it is not known whether the mutation occurred within the part of the gene structure that determines reovirus growth in the heart.

Finally, we believe that the experimental approach in the studies reported here, and the associated findings, provide a novel system for studies of viral myocarditis at a molecular genetic level.

\section{Acknowledgments}

This work was done during the tenure of a Research Fellowship from the American Heart Association, Massachusetts Affiliate, Inc., and was also supported by a Fellowship Grant from the Japan Heart Foundation and in part by NIH grants AI-73178 and HL-36141. 


\section{References}

1. Sharpe, A. H., R. F. Ramig, T. A. Mustoe, and B. N. Fields. 1978. A genetic map of reovirus. I. Correlation of genome RNAs between serotypes 1, 2, and 3 . Virology. 84:63-74.

2. Schiff, L. A., and B. N. Fields. 1990. Reoviruses and their replication. In Virology. B. N. Fields, editor. Raven Press, Ltd., New York. 1275-1306.

3. Tyler, K. L., and B. N. Fields. Reoviruses. In Virology. B. N. Fields, editor. Raven Press, Ltd., New York. 1307-1328.

4. Weiner, H. L., K. A. Ault, and B. N. Fields. 1980. Interactions of reovirus with cell surface receptors. I. Murine and human lymphocytes have a receptor for the hemagglutinin of reovirus type 3. J. Immunol. 124:2143-2148.

5. Weiner, H. L., D. Drayna, D. R. Averill, Jr., and B. N. Fields. 1977. Molecular basis of reovirus virulence: role of the S1 gene. Proc. Natl. Acad. Sci. USA. 74:5744-5748.

6. Drayna, D., and B. N. Fields. 1982. Genetic studies on the mechanism of chemical and physical inactivation of reovirus. J. Gen. Virol. 63:149-159.

7. Hrdy, D. B., D. N. Rubin, and B. N. Fields. 1982. Molecular basis of reovirus neurovirulence: role of the M2 gene in avirulence. Proc. Natl. Acad. Sci. USA. 79:1298-1302.

8. Sharpe, A. H., and B. N. Fields. 1982. Reovirus inhibition of cellular RNA and protein synthesis: role of the S4 gene. Virology. 122:381-391.

9. Ahmed, R., and B. N. Fields. 1982. Role of the $\$ 4$ gene in the establishment of persistent reovirus infection in L cells. Cell. 28:605-612.

10. Sherry, B., F. J. Schoen, E. Wenske, and B. N. Fields. 1989. Derivation and characterization of an efficiently myocarditic reovirus variant. J. Virol. 63:4840-4849.

11. Sherry, B., and B. N. Fields. 1989. The reovirus M1 gene, encoding a vira core protein, is associated with the myocarditic phenotype of a reovirus variant. $J$. Virol. 63:4850-4856.

12. Bloch, K. D., J. G. Seidman, J. D. Naftilan, J. T. Fallon, and C. F. Seidman. 1986. Neonatal atria and ventricles secrete atrial natriuretic factor via tis sue-specific secretory pathways. Cell. 47:695-702.

13. Ramig, R. F., R. K. Cross, and B. N. Fields. 1977. Genome RNAs and polypeptides of reovirus serotypes 1, 2, and 3. J. Virol. 22:726-733.

14. Brown, E. G., M. L. Nibert, and B. N. Fields. 1983. The L2 gene of reovirus serotype 3 controls the capacity to interfere, accumulate deletions, and establish persistent infection. In Double-Stranded RNA Viruses. R. W. Compans, and D. H. L. Bishop, editors. Elsevier Science Publishing, Inc., New York. 275-287.

15. Virgin, H. W. IV, R. Bassel-Duby, B. N. Fields, and K. L. Tyler. 1988 Antibody protects against lethal infection with the neurally spreading reovirus type 3 (Dearing). J. Virol. 62:4594-4604.

16. Lentner, C., editor. 1982. GEIGY Scientific Tables. Vol. 2. Introduction to Statics. CIBA-GEIGY Corp., West Caldwell, NJ. 152-162.

17. Zak, R. 1973. Cell proliferation during cardiac growth. Am. J. Cardiol. 31:211-219.

18. Morkin, E., and T. Ashford. 1968. Myocardial DNA synthesis in experimental cardiac hypertrophy. Am. J. Physiol. 215:1409-1413.

19. Walters, M. N.-I., R. A. Joske, P. J. Leak, and N. F. Stanley. 1963. Murine infection with reovirus: I. Pathology of the acute phase. Br. J. Exp. Pathol. 44:427-436.

20. Walters, M. N.-I., P. J. Leak, R. A. Joske, N. F. Stanley, and D. H. Perret. 1965. Murine infection with reovirus. III. Pathology of infection with types 1 and 2. Br. J. Exp. Pathol. 46:200-212.

21. Hassan, S. A., E. R. Rabin, and J. L. Melnick. 1965. Reovirus myocarditis in mice; an electron microscopic immunofluorescent, and virus assay study. Exp. Mol. Pathol. 4:66-80.

22. Goller, T., J. Galle, H. Eggers, and B. Bultmann. 1986. Experimental reovirus myocarditis in newborn mice. Virchows Arch. B Cell Pathol. 50:373386.
23. Stangl, E., W. Aschauer, J. Zahringer, and G. Hubner. 1987. Reovirus myocarditis. Eur. Heart J. 8(Suppl. j):407-409.

24. Joske, R. A., D. D. Keall, P. J. Leak, N. F. Stanley, and M. N. I. Walters 1964. Hepatitis-encephalitis in humans with reovirus infection. Arch. Intern. Med. 113:811-816.

25. Woodruff, J. F. 1980. Viral myocarditis; a review. Am. J. Pathol. 101:427479 .

26. Duke, G. M., J. E. Osorio, and A. C. Palmenberg. 1990. Attenuation of Mengo virus through genetic engineering of the $5^{\prime}$ noncoding poly $(\mathrm{C})$ tract. $\mathrm{Na}$ ture (Lond.). 343:474-476.

27. Schwimmbeck, P. L., H. P. Schultheiss, and B. E. Strauer. 1989. Identification of a main autoimmunologenic epitope of the adenine nucleotide translocator which cross-reacts with Coxsackie B3 virus; use in the diagnosis of myocarditis and dilated cardiomyopathy. Circulation. 80(Suppl 2):665a. (Abstr.)

28. Schultheiss, H. P., P. Schwimmbeck, and H. D. Bolte. 1983. Autoantibodies against the adenine nucleotide translocator in myocarditis and dilated cardiomyopathy. In Viral Heart Disease. H. D. Bolte, editor. Springer-Verlag, New York. 131-143.

29. Beisel, K. W., J. Srinivasappa, B. J. M. Booth, and B. S. Prabhakar. 1989. Identification of an antigenic epitope shared between Coxsackievirus B4 and murine alpha cardiac myosin heavy chain. Circulation. 80(Suppl 2):673a. (Abstr.)

30. Neu, N., K. W. Beisel, M. D. Traystman, N. R. Rose, and S. W. Craig. 1987. Autoantibodies specific for the cardiac myosin isoform are found in mice susceptible to Coxsackievirus $\mathrm{B}_{3}$-induced myocarditis. J. Immunol. 138:24882492.

31. Matsumori, A., C. Kawai, C. S. Crumpacker, and W. A. Abelmann. 1987. The use of animal models for preventive and therapeutic trials of myocarditis. In Pathogenesis of Myocarditis and Cardiomyopathy. C. Kawai, and W. H. Abelmann, editors. University of Tokyo Press, Tokyo, Japan. 37-47.

32. Huber, S. A., P. A. Lodge. 1986. Coxsackievirus B-3 myocarditis; identification of different pathogenic mechanisms in DBA/2 and Balb/c mice. Am. J. Pathol. 122:284-291.

33. Wolfgram, L. J., K. W. Beisel, A. Herskowitz, and N. R. Rose. 1986. Variations in the susceptibility to Coxsackievirus $B_{3}$-induced myocarditis among different strains of mice. J. Immunol. 136:1846-1852.

34. Paque, R. E., C. J. Gauntt, T. J. Nealon, and M. D. Trousdale. 1978. Assessment of cell-mediated hypersensitivity against Coxsackie virus B3 viral-induced myocarditis utilizing hypertonic salt extracts of cardiac tissue. J. Immunol. 120:1672-1678.

35. Weiner, H. L., M. L. Powers, and B. N. Fields. 1980. Absolute linkage of virulence and central nervous system cell tropism of reoviruses to viral hemagglutinin. J. Infect. Dis. 141:609-616.

36. Dichter, M. A., and H. L. Weiner. 1984. Infection of neuronal cell cultures with reovirus mimics in vitro patterns of neurotropism. Ann. Neurol. 16:603610.

37. Tyler, K. L., R. T. Bronson, K. B. Byers, and B. N. Fields. 1985. Molecular basis of viral neurotropism; experimental reovirus infection. Neurology. 35:8892.

38. Maratos-Flier, E., M. J. Goodman, B. N. Fields, and C. R. Kahn. 1985. Differential effects of viral infection on islet and pituitary cell lines. Endocrinology. 116:2430-2437.

39. Bodkin, D. K., and B. N. Fields. 1989. Growth and survival of reovirus in intestinal tissue: Role of the L2 and S1 genes. J. Virol. 63:1188-1193.

40. Drayna, D., and B. N. Fields. 1982. Activation and characterization of the reovirus transcriptase: genetic analysis. J. Virol. 41:110-118.

41. Morozov, S. Y. 1989. A possible relationship of reovirus putative RNA polymerase to polymerases of positive-strand RNA viruses. Nucleic Acids Res. 17:5394. 